\title{
In-Vitro Fertilization Outcome Predictors in Women With High Baseline Follicle-Stimulating Hormone Levels: Analysis of Over 1000 Cycles From A Tertiary Center
}

\author{
Gülnaz Sahin ${ }^{1}$, Aysin Akdogan'1 ${ }^{1}$ Murat Hakan Aydın², Mustafa Agah Tekindal ${ }^{3}$, Ege Nazan Tavmergen Göker ${ }^{1,2}$, \\ Erol Tavmergen ${ }^{1,2}$ \\ ${ }^{1}$ Ege University Family Planning and Infertility Treatment and Research Center, Ankara cad., 35100 Bornova, \\ Izmir, Turkey \\ 2Deparment of Obstetrics and Gynecology, Ege University Faculty of Medicine, Ankara cad., 35100, Bornova, \\ Izmir, Turkey \\ ${ }^{3}$ Selcuk University, Veterinary Faculty, Department of Biostatistics 42003 Selçuklu, Konya, Turkey
}

\begin{abstract}
Objective: The present study aimed to evaluate reproductive outcomes and determine the predictors of clinical pregnancy and live birth in women with elevated baseline follicle-stimulating hormone (FSH) levels, who have undergone intracytoplasmic sperm injection (ICSI) treatment.
\end{abstract}

Methods: This retrospective study included 1011 ICSI cycles of women with high baseline FSH levels ( $>10$ IU/L), from a tertiary university IVF center between 2010 and 2015. Logistic regression analysis was performed to evaluate the prognostic factors of clinical pregnancy and live birth.

Results: Among the 1011 ICSI cycles, the clinical pregnancy and live birth rates per oocyte retrieval were $19.5 \%$ and $14.3 \%$, respectively. The live birth rates were $21.1 \%$ and $1.7 \%$ in women aged $\leq 30$ years and those aged $\geq 40$ years, respectively. In addition, the live birth rate was 1.47 -fold higher in women from whom $>3$ oocytes were retrieved, compared to those from whom $\leq 3$ oocytes were retrieved $(p=0.047)$. Logistic regression analysis indicated that the age categories $\leq 30 y, 36-39 y$ and $\geq 40 y$, level of baseline FSH ( $\geq 20 \mathrm{IU} / \mathrm{L})$ and the ovarian response ( $\leq 3$ or $>3$ oocytes retrieved) were significantly associated with live birth.

Conclusions: Our study indicated that age, baseline FSH level, and ovarian response are independent predictive factors for clinical pregnancy and live birth among women with baseline FSH levels > 10 IU/L.

Keywords: Aging, assisted reproductive techniques, follicle stimulating hormone, pregnancy rate, live birth

\section{INTRODUCTION}

Prediction regarding assisted reproductive technology (ART) success as a live birth after treatment is an important consideration for the clinician and the infertile couple. Women's age and ovarian reserve are important markers for ovarian response and; therefore, ART treatment outcomes. Pregnancy rates decrease and miscarriage rates increase with advanced age, and age is one of the most important predictors of in-vitro fertilization (IVF) success (Broekmans et al., 2006; van Loendersloot et al., 2010; Broer et al., 2013; McLernon et al., 2016). Both the declining number and the quality of oocytes with aging are associated with decreased success rates in ART cycles.

Ovarian response to stimulation and reproductive potential can be different in women of similar age, according to the individual's ovarian reserve (ASRM, 2015). Along with women's age, the association of ovarian reserve and ART outcomes has been the subject of studies (Broer et al.,2013; Lukaszuk et al., 2014; Ligon et al., 2019; Wang et al., 2018; Metello et al., 2019). Ovarian reserve tests have predictive capacity for ovarian response to gonadotropin stimulation (Jayaprakasan et al., 2010; La Marca et al., 2010; Broer et al.,2013; Nelson et al., 2015; Hamdine et al., 2015). However, their prediction of pregnancy during ART cycles is limited (Broekmans et al.,2006; Broer et al., 2013). Anti-Müllerian hormone $(\mathrm{AMH})$, antral follicle count (AFC), and baseline FSH are the most commonly tests used to evaluate ovarian reserve. Although AMH and AFC are more informative biomarkers of ovarian reserve and response (Nelson, 2013; La Marca et al., 2016; Tal \& Seifer, 2017), baseline FSH level is still one of the commonly used test for daily practices. It is generally accepted that the ovarian reserve is low when the FSH level exceeds 10-12 IU/L (Fang et al., 2015). High FSH levels are associated with a low oocyte yield and high cycle cancellation rates (Creus et al., 2000; Chuang et al., 2003; Abdalla \& Thum, 2004; Thum et al., 2009; Gingold et al., 2015). In a previous meta-analysis, the baseline FSH level, female age, infertility duration, and oocyte number were predictors of IVF outcomes (van Loendersloot et al., 2010). Elevated baseline FSH level is one of the used criteria for diagnosis of diminished ovarian reserve (DOR) in clinical practice (Pastore et al., 2018). Counseling and management of patients with high baseline FSH levels, as reflecting DOR, needs further consideration.

Assisted reproductive technologies are economical burden and very stressful for couples. Evaluation of the expected pregnancy rate according to the characteristics of the couple is very important, and provides information on the realistic chance of pregnancy. The present study aimed to evaluate reproductive outcomes and determine the predictors of clinical pregnancy and live birth in women with baseline FSH levels $>10 \mathrm{IU} / \mathrm{L}$, who have undergone intracytoplasmic sperm injection (ICSI) treatment.

\section{MATERIALS AND METHODS}

This retrospective study included 1011 oocyte retrieval/ICSI cycles of women aged 19-45 years with high baseline FSH (>10 IU/L), and performed in a single tertiary in vitro fertilization (IVF) center between 2010-2015. Each patient was included only once. The Institutional Ethics Committee approved the study (No.: 16-2/15). The cycles that used antagonist protocol matched the inclusion criteria. All baseline FSH measurements were performed at the beginning of the ovarian stimulation. Data on clinical 
variables and controlled ovarian stimulation (COS)/ICSI treatment outcomes were retrieved from the IVF database and the patient medical records. COS was started on day 2 or 3 of the menses, with recombinant FSH or urinary $\mathrm{FSH} /$ human menopausal gonadotropin (HMG). When the lead follicle diameter reached $12 \mathrm{~mm}$, the antagonist was added. Human chorionic gonadotropin (hCG) was used for follicular maturation when the lead follicle reached $18 \mathrm{~mm}$. Oocyte aspiration was performed 34-36 hours after hCG administration. All mature oocytes underwent the ICSI procedure 2-4 hours after aspiration. Embryo transfer was performed on day 2-5 of the culture period. According to the directives of the Ministry of Health, a maximum of two embryos were transferred. Progesterone vaginal gel ( 90 $\mathrm{mg} /$ day) was used for luteal phase support. Additionally, a single-dose hCG injection (5000 IU) was administered after day 4 or 5 of the embryo transfer. A visible intrauterine sac on ultrasound 3 weeks after embryo transfer was considered a clinical pregnancy. All pregnancy outcomes were recorded. Miscarriage was defined as a loss of a clinical pregnancy before 24 weeks of gestation. Live birth was defined as the birth of a viable infant after 24 weeks of pregnancy.

The serum baseline FSH levels were quantitatively determined using a chemiluminescent immunometric assay (Access ${ }^{\circledR}$, Beckman Coulter, Inc., Brea, CA, USA) and analyzed using the UniCel ${ }^{\circledR}$ DxI 800 Access $^{\circledR}$ Immunoassay System (Beckman Coulter, Inc.). The range for FSH measurement was 0.2-200 IU/L. Baseline hormone measurements were routinely performed on day 2 or 3 of menses. All measurements were performed at the morning of the start of COS.

To evaluate the influence of age on outcomes, the women were divided into the following groups according to age: group A ( $\leq 30$ years old), group B ( $31-35$ years old), group C (36-39 years old), and group D ( $\geq 40$ years old). Additionally, the women were divided into the following groups according to their FSH level: level 1 (10-14.9 IU/L), level 2 (15-20 IU/L), and level 3 (>20 IU/L).

\section{Statistical analysis}

Continuous variables were compared among age groups by variance analysis or the Kruskal-Wallis test, depending on the homogeneity and normality of the variables. For multiple comparisons we used the adjusted Bonferroni
(Bonferroni-Dunn) test. Categorical variables were compared using the chi-square test or the Fischer's exact test where appropriate. Logistic regression analysis was performed to evaluate the predictors of clinical pregnancy and live birth. All statistical analyses were performed using the SPSS software (SPSS ver. 17.0, SPSS Inc., Chicago, $\mathrm{IL}$, USA). Statistical significance was defined as a $p$-value $<0.05$.

\section{RESULTS}

A total of 1011 oocyte retrieval/ICSI cycles were analyzed. In addition to a decreased ovarian reserve, $7.4 \%$ of the cycles were performed for tubal factor infertility and $30.8 \%$ were performed for male factor infertility. Table 1 shows the demographics and ICSI outcomes of the study participants. Their mean age was $35.1 \pm 4.6$ years, their mean FSH level was $14.8 \pm 5.1 \mathrm{IU} / \mathrm{L}$, and the mean number

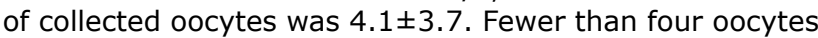
were obtained in over half of the cycles (53.9\%). Twelve women $(1.2 \%)$ showed a hyper-response to COS and produced more than 20 oocytes, although their FSH levels were $>10 \mathrm{IU} / \mathrm{L}$

Of the 1011 cycles analyzed, 826 (81.7\%) involved an embryo transfer procedure. In the remaining 185 cycles $(18.3 \%)$, embryo transfer could not be performed because of the absence of a mature oocyte $(8.2 \%)$, fertilization or cleavage failure $(7.4 \%)$, and other reasons $(2.6 \%)$. A single embryo transfer was performed in $62.3 \%$ of the cycles.

The clinical pregnancy rates were 19.5\% (197/1011) per oocyte retrieval, and $23.8 \%(197 / 826)$ per embryo transfer. Biochemical pregnancy was noted in $1.9 \%$ $(20 / 1011)$ of the cycles, and $0.3 \%(3 / 1011)$ had an ectopic pregnancy, which was considered preclinical pregnancy failure. Miscarriage was noted in $5.1 \%(52 / 1011)$ of the cycles and $26.4 \%(52 / 197)$ of clinical pregnancies. The live birth rates were $14.3 \%(145 / 1011)$ per oocyte retrieval and $17.5 \%(145 / 826)$ per embryo transfer cycle.

The ICSI cycle characteristics of the different age groups (groups A, B, C, and D) are presented in Table 2 .

Although the total gonadotropin used was significantly lower in women aged $<36$ years than in those aged $\geq 36$ years, their peak estradiol level, number of total and metaphase 2 oocytes, and the number of embryos was

Table 1. Demographics and ICSI outcomes of the study participants.

\begin{tabular}{|c|c|c|}
\hline & $\begin{array}{c}\text { Overall } \\
\text { mean土 SD }\end{array}$ & $\begin{array}{l}\text { Overall } \\
\text { min-max }\end{array}$ \\
\hline Age (years) & $35 \pm 4.65$ & $19-45$ \\
\hline Baseline FSH (IU/L) & $14.8 \pm 5.1$ & $10-39.6$ \\
\hline Baseline LH (IU/L) & $6.6 \pm 3.3$ & $1-40$ \\
\hline Gonadotropin dose (IU) & $2384 \pm 825$ & $900-6650$ \\
\hline No. of oocytes & $4.1 \pm 3.7$ & $0-28$ \\
\hline No. of metaphase II oocytes & $3.0 \pm 2.8$ & $0-25$ \\
\hline Fertilization rate $(\%)$ & $74.5 \pm 31.5$ & $0-100$ \\
\hline No. of embryos & $2.5 \pm 2.5$ & $0-23$ \\
\hline No. of embryos transferred & $1.3 \pm 0.4$ & $1-2$ \\
\hline Clinical pregnancy rate/ opu \%, (n) & 19.5 & $197 / 1011$ \\
\hline Clinical pregnancy rate/ ET \%, (n) & 23.8 & $197 / 826$ \\
\hline Live birth rate /opu \%, (n) & 14.3 & $145 / 1011$ \\
\hline Live birth rate /ET \%, (n) & 17.5 & $145 / 826$ \\
\hline
\end{tabular}

Opu: oocyte pick-up

ET: embryo transfer 


\begin{tabular}{|c|c|c|c|c|c|}
\hline & $\begin{array}{c}\text { Group } A \\
\leq 30 \text { years } \\
n=180 \\
\end{array}$ & $\begin{array}{c}\text { Group B } \\
31-35 \text { years } \\
n=336 \\
\end{array}$ & $\begin{array}{c}\text { Group C } \\
36-39 \text { years } \\
n=379 \\
\end{array}$ & $\begin{array}{c}\text { Group } D \\
\geq 40 \text { years } \\
n=116 \\
\end{array}$ & p-value \\
\hline Baseline FSH (IU/L) & $14.6 \pm 5.3$ & $14.1 \pm 4.3$ & $14.1 \pm 4.3$ & $16.0 \pm 5.8^{\mathrm{b}}$ & $<0.01^{\Omega}$ \\
\hline $\begin{array}{l}\text { FSH level I (\%) } \\
\text { FSH level II (\%) } \\
\text { FSH level III (\%) }\end{array}$ & $\begin{array}{l}71.1 \\
16.7 \\
12.2\end{array}$ & $\begin{array}{c}71.7 \\
19.6 \\
8.6\end{array}$ & $\begin{array}{l}60.4 \\
24.5 \\
15.0\end{array}$ & $\begin{array}{l}56.9 \\
23.3 \\
19.8\end{array}$ & $<0.01^{¥}$ \\
\hline Baseline LH (IU/L) & $6.5 \pm 2.8$ & $6.5 \pm 3.4$ & $6.7 \pm 3.6$ & $6.6 \pm 2.8$ & $0.9^{ \pm}$ \\
\hline Gonadotropin dose (IU) & $2196 \pm 742$ & $2257 \pm 773$ & $2555 \pm 844^{\mathrm{ab}}$ & $2496 \pm 911^{\mathrm{ab}}$ & $0.05^{\Omega}$ \\
\hline Peak E2 level (pg/mL) & $1000 \pm 884$ & $764 \pm 560^{a}$ & $654 \pm 542^{a}$ & $556 \pm 476^{\mathrm{ab}}$ & $<0.01^{E}$ \\
\hline No. of oocytes & $6.0 \pm 5.1$ & $4.5 \pm 3.4^{a}$ & $3.4 \pm 3.1^{\mathrm{ab}}$ & $2.5 \pm 2^{\mathrm{ab}}$ & $0.01^{\Omega}$ \\
\hline $\begin{array}{l}\text { Poor response }(\%) \\
(0-3 \text { oocytes })\end{array}$ & 37.8 & 46.4 & $62.3^{\mathrm{ab}}$ & $73.3^{\mathrm{abc}}$ & $0.001^{*}$ \\
\hline No. of mII oocytes & $4.2 \pm 4$ & $3.3 \pm 2.6^{a}$ & $2.5 \pm 2.4^{\mathrm{ab}}$ & $1.9 \pm 1.6^{\mathrm{ab}}$ & $0.01^{ \pm}$ \\
\hline Fertilization rate $(\%)$ & $71.7 \pm 32.4$ & $75.2 \pm 29.1$ & $75 \pm 32.5$ & $75.9 \pm 34.1$ & $0.9^{*}$ \\
\hline No. of embryos & $3.5 \pm 3.3$ & $2.8 \pm 2.3^{\mathrm{a}}$ & $2.1 \pm 2.2^{\mathrm{ab}}$ & $1.5 \pm 1.4^{\mathrm{abc}}$ & $0.01^{ \pm}$ \\
\hline No. of embryos transferred & $1.1 \pm 0.3$ & $1.2 \pm 0.4^{a}$ & $1.5 \pm 0.5^{\mathrm{ab}}$ & $1.4 \pm 0.5^{\mathrm{ab}}$ & $0.01^{\Omega}$ \\
\hline Embryo transfer/opu (\%) & 83.9 & 86.9 & $79.4^{\mathrm{b}}$ & $70.7^{a b c}$ & $0.001^{*}$ \\
\hline Clinical pregnancy rate (\%) & $23.9(43 / 180)$ & $23.5(79 / 336)$ & $18.2(69 / 379)$ & $5.2(6 / 116)^{\mathrm{abc}}$ & $0.001^{*}$ \\
\hline Live birth rate $(\%)$ & $21.1(38 / 180)$ & $19.3(65 / 336)$ & $10.6(40 / 379)^{\mathrm{ab}}$ & $1.7(2 / 116)^{\mathrm{abc}}$ & $0.001^{*}$ \\
\hline Miscarriage/clinical preg $(\%, \mathbf{n})$ & $11.6(5 / 43)$ & $17.7(14 / 79)$ & $42.0(29 / 69)^{a b}$ & $66.7(4 / 6)^{\mathrm{ab}}$ & $0.001^{*}$ \\
\hline
\end{tabular}

a Different from group $A$

b Different from group B

c Different from group $C$

$\Omega$ One Way ANOVA

* Chi Square Test

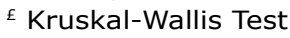

Pairwise Comparison with Bonferroni and Bonferroni-Dunn Test

significantly higher than those who were older. Additionally, an increase in age was significantly associated with a high rate of poor response $(0-3$ oocytes $)(p<0.05)$. Among women aged $\geq 40$ years, the rate of poor response was significantly high $(73.3 \%$ of the cycles, $p<0.001$ ) (Table $2)$. Additionally, there were negative correlations between the number of oocytes with age $(r=-0.309, p<0.001)$ and baseline FSH levels $(r=-0.313, p<0.001)$.

Among women aged $\leq 30$ years, the clinical pregnancy and live birth rates were $23.9 \%$ and $21.1 \%$, respectively. Although the majority of women $(89.4 \%)$ in this group had a single embryo transfer, the outcomes were acceptable. On the other hand, among women aged $\geq 40$ years, the clinical pregnancy and live birth rates were $5.2 \%$ and $1.7 \%$, respectively. The miscarriage rate significantly increased with age $(p<0.05)$ and baseline FSH level (Fig $1 \mathrm{a}, 1 \mathrm{~b})$. The miscarriage rates of clinical pregnancies were $42 \%$ and $66.7 \%$ among women aged $36-39$ years and those aged $\geq 40$ years, respectively.

We ran a logistic regression analysis to evaluate the factors related to clinical pregnancy and live birth. The categories of age, level of baseline $\mathrm{FSH}$, ovarian response ( $\leq 3$ or $>3$ oocytes retrieved) and number of transferred embryos were applied to the model. Categories of age $(\leq 30,36-39, \geq 40)$, extreme baseline FSH level ( $\geq 20 \mathrm{IU} / \mathrm{L})$ and ovarian response ( $\leq 3$ or $>3$ oocytes) were found as independent predictors of live birth (Table 3 ).

As expected, an increase in age was significantly associated with decreased live birth rates in multivariate analyses. The live birth rate was 2.2 -fold lower in women aged $36-39$ years than in those aged $\leq 30$ years $(p=0.006)$.
Conspicuously, the live birth rate was 12.48 -fold lower in women aged $\geq 40$ years than in those aged $\leq 30$ years $(p=0.001)$. The baseline FSH level was another significant factor for live birth. The live birth rate was 2.68 -fold lower in women with baseline FSH levels $>20 \mathrm{IU} / \mathrm{L}$ than in those with FSH levels of $10-14.9 \mathrm{IU} / \mathrm{L}(p=0.02)$. The number of retrieved oocytes was another significant factor for clinical pregnancy and live birth. The live birth rate was 1.47 -fold higher in women from whom $>3$ oocytes were retrieved than in those from whom $\leq 3$ oocytes were retrieved ( $p=$ .047).

To find miscarriage predictors, we used logistic regression analysis, and only age was found to be an independent factor for predicting miscarriage.

\section{DISCUSSION}

The present study showed that women with high baseline FSH levels have different cycle outcomes according to age. The pregnancy and live birth rates were higher in younger women than in older women, although all had high baseline FSH levels. In addition to age, the extreme FSH level $(>20 \mathrm{IU} / \mathrm{ml}$ ) and response to stimulation (obtaining $\leq 3$ or $>3$ oocytes) were independent factors affecting live birth in our large cohort of women with high FSH levels. When the retrieved oocyte number exceeded 3, the clinical pregnancy and live birth chances increased 1.84 and 1.47-fold, respectively, in our cohort. These findings indicate that if a woman responds well to gonadotrophin stimulation, the possibilities of a pregnancy and live birth increase. Thus, efforts to obtain additional oocytes are much valuable in this group of women. 


\section{Figure 1a: Pregnancy outcomes of age groups}

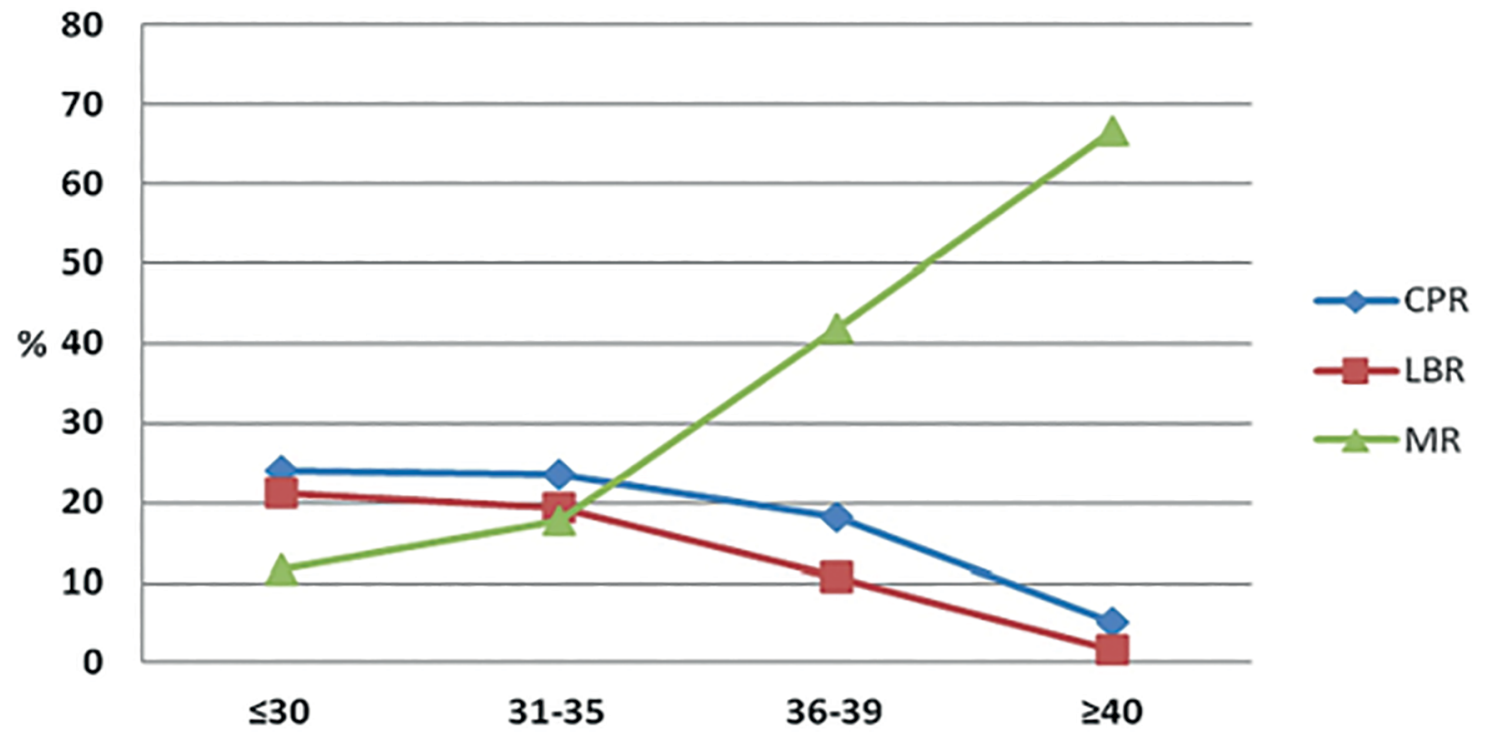

Figure 1b: Pregnancy outcomes of FSH groups

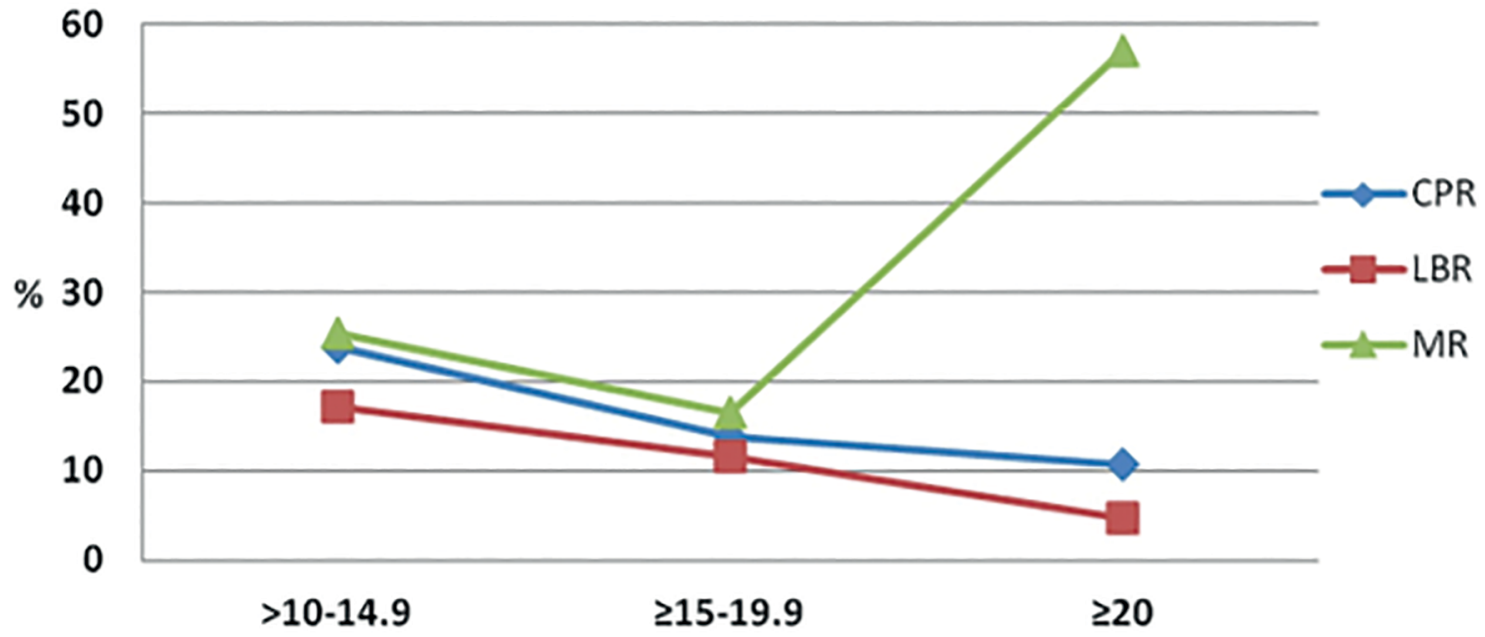

Figure 1. Pregnancy outcomes. 1a. Pregnancy outcomes according to age. 1b. Pregnancy outcomes according to FSH levels.

(\%) CPR: Clinical pregnancy rate per opu

(\%) LBR: Live birth rate per opu (\%)

MR: Miscarriage rate per clinical pregnancy

The prediction of pregnancy after IVF is an important issue in reproductive medicine. Several studies have attempted to develop prediction models for IVF outcomes (Nelson \& Lawlor 2011; van Loendersloot et al.,2013; McLernon et al., 2016; Vaegter et al., 2017; Leijdekkers et al., 2018). Reproductive aging is a well-known cause of poor ovarian reserve, and age is the most established predictor of IVF outcomes (Vaegter et al., 2017). Apart from poor ovarian response with aging, studies have found a high rate of chromosomal aberrations that can lead to miscarriage in older women (Bartmann et al., 2004;
Demko et al., 2016; Simon et al., 2018). Therefore, the age-related decline in oocyte quality is an important factor in these women.

Consistent with the previous reports, in the present study, women aged $\geq 40$ years with high baseline FSH levels showed a high poor response rate of $73.3 \%$ as less than four oocytes were retrieved. Additionally, the live birth probability was 12.4 -fold lower in these women than in those aged $\leq 30$ years. Moreover, the rate of miscarriage per clinical pregnancy constantly increased with age; and among women aged $\geq 40$ years; the rate of miscarriage per 
Table 3. Evaluation of the predictors of clinical pregnancy and live birth.

\begin{tabular}{|c|c|c|c|c|c|c|}
\hline & \multicolumn{3}{|c|}{ Clinical pregnancy } & \multicolumn{3}{|c|}{ Live Birth } \\
\hline & $p$ value & OR & $95 \% \mathrm{CI}$ & $p$ value & OR & $95 \% \mathrm{CI}$ \\
\hline Age $\leq \mathbf{3 0}$ years & .008 & & & .001 & & \\
\hline Age $31-35$ years & .773 & .936 & $.595-1.472$ & .495 & .848 & $.528-1.362$ \\
\hline Age $36-39$ years & .227 & .729 & $.436-1.217$ & .006 & .453 & $.257-.801$ \\
\hline Age $\geq \mathbf{4 0}$ years & .001 & .211 & $.082-.538$ & .001 & .080 & $.018-.350$ \\
\hline Baseline FSH 10-14.9 IU/L & .209 & & & .078 & & \\
\hline Baseline FSH 15-20 IU/L & .128 & .705 & $.449-1.106$ & .460 & .832 & $.511-1.355$ \\
\hline Baseline FSH $\geq 20 \mathrm{IU} / \mathrm{L}$ & .040 & .698 & $.373-1.305$ & .027 & .373 & $.155-.895$ \\
\hline No of oocytes $(>3)$ & .001 & 1.846 & $1.274-2.645$ & .047 & 1.474 & $.978-2.222$ \\
\hline No. of transferred embryos & .059 & 1.451 & $.986-2.136$ & .282 & 1.270 & $.822-1.962$ \\
\hline
\end{tabular}

clinical pregnancy was high at $66 \%$. In our study, only age was found to be significantly associated with miscarriage, and this finding supports the belief that aging is associated with a decline in oocyte quality. Although the miscarriage rate increased as the FSH level increased, this association was not found to be significant in the multivariate analysis.

In some women, fertility declines at an earlier age. Therefore, the ovarian reserve might differ among women of the same age. The term "ovarian reserve" is considered as the number and quality of follicles present in the ovary at "any given time" (Broekmans et al., 2006). Although the antral follicle count and anti-Müllerian hormone levels are more informative biomarkers of ovarian response (Nelson, 2013), an elevated early follicular FSH level is considered one of the indicators of a diminished ovarian reserve (DOR) (Chuang et al., 2003); and in daily practice, it is one of the commonly used tests for DOR (Buyuk et al., 2011). It has been generally accepted that the ovarian reserve is low when the FSH level exceeds 10-12 IU/L (Fang et al., 2015), and high FSH levels have been shown to be associated with low oocyte yield (Thum et al., 2009; Gingold et al., 2015). A previous model for the prediction of ovarian response in antagonist cycles showed that age, antral follicle count, and baseline FSH and LH levels could predict the ovarian response (Broekmans et al.,2014). Similarly, in antagonist protocols, the baseline $\mathrm{FSH}$, antiMüllerian hormone, and antral follicle count were found to be good predictors for ovarian stimulation (Tsakos et al.,2014). In addition, nomograms aiming to calculate the starting gonadotropin dose according to age and the $\mathrm{FSH}$, anti-Müllerian hormone, and antral follicle count have already been published (La Marca et al., 2012; 2013). Papaleo et al. (2016) suggested this nomogram as a useful tool to selecting the gonadotropin dose for stimulation in ART treatments.

van Rooij et al. (2003) evaluated the influence of age and FSH level on IVF outcomes. They found that aging mainly affects the implantation and pregnancy rates owing to poor oocyte quality and that elevated $\mathrm{FSH}$ levels are associated with cycle cancellation owing to the poor response to gonadotropins. They stated that the implantation and pregnancy rates might be reasonable if a young woman with high FSH levels produce oocytes. Chuang et al. (2003) suggested that age, but not the FSH level is independently associated with pregnancy rates, and both a high FSH level and aging are significantly associated with the numbers of oocytes collected, fertilized oocytes, and transferred embryos. These results are consistent with the conclusion that age is a better predictor of oocyte quality, and baseline FSH level is a better predictor of oocyte number (Toner, 2003).
According to our study results, both high FSH levels and aging are significantly associated with reduced numbers of oocytes. Consistent with the findings of previous studies, our study showed that in young women (aged $\leq 30$ years) with poor ovarian reserve, clinical pregnancy and live birth rates were acceptable at $23.9 \%$ and $21.1 \%$, respectively, although the majority of the women had a single embryo transfer. On the other hand, in the present study, not only age but also the extreme baseline FSH level ( $>20 \mathrm{IU} / \mathrm{L}$ ) was found to be a significantly independent predictor of pregnancy and live birth. This observation was consistent with the finding of a previous meta-analysis that included pooled data from five studies, which showed that a high baseline $\mathrm{FSH}$ level is associated with low pregnancy rates and that $\mathrm{FSH}$ is one of the significant predictive factor for pregnancy outcome (van Loendersloot et al., 2010).

The outcomes of low-prognosis patients have been of a special interest in the field of ART. Chang et al.(2018), reported lower clinical pregnancy rates with higher miscarriages in older women with diminished ovarian reserve (defined by elevated $\mathrm{FSH} \geq 10 \mathrm{IU} / \mathrm{L}, \mathrm{AMH}$ level of $<1.1 \mathrm{ng} / \mathrm{ml}$ and $\mathrm{AFC}<6$ ), than in younger women with diminished ovarian reserve. Levin et al. (2015) evaluated the IVF outcome in women with baseline FSH levels of 10.0-11.9 IU/L, which were considered as "borderline FSH levels." The authors reported that the number of embryos was the only predictor of clinical pregnancy. Huang et al. (2015) evaluated the predictive factors of IVF outcomes in 58 women with high baseline FSH levels ( $\geq 12 \mathrm{IU} / \mathrm{L}$ ). They found that ovarian stimulation parameters (the number of mature follicles on trigger day, number of oocytes, and developed embryos) are predictive factors for the IVF outcome in those selected group. Kushnir et al. (2018), evaluated IVF outcomes of 291 women with high baseline FSH levels ( $>20 \mathrm{IU} / \mathrm{L})$. The highest live birth rates are from women $<35$ years at $(17.2 \%)$, and the lowest rates from women $>42$ years $(1.9 \%)$.

The most important endpoint is the live birth rate of ART treatments. We attempted to analyze the live birth rates and predictive factors for live birth in our large data set of women with baseline FSH levels $>10 \mathrm{IU} / \mathrm{L}$. The strength of this study is that it included more than 1000 oocyte retrieval cycles from a single tertiary center. The limitation is the retrospective nature of the study. In addition, we collected the data from patients who underwent oocyte retrieval; therefore, the prior cancellation before the oocyte retrieval procedure was not included in this study.

In conclusion, age, baseline FSH level, and the ovarian response as; $\leq 3$ or $>3$ oocytes retrieved, are significant predictors of clinical pregnancy and live birth among women with high baseline FSH level. These findings can be used 
to appropriately counsel women undergoing ART in order to ensure that these women have realistic expectations.

\section{CONFLICT OF INTEREST}

The authors declare that they have no conflict of interest.

\section{Corresponding Author:}

Gülnaz Sahin,

Family Planning and Infertility Treatment and Research Center

Ege University

Ankara cad., Bornova, Izmir, Turkey

E-mail: gsahini@msn.com

\section{REFERENCES}

Abdalla $H$, Thum MY. An elevated basel FSH reflects a quantitative rather than qualitative decline of the ovarian reserve. Hum Reprod. 2004;19:893-8. PMID: 15016786 DOI: $10.1093 /$ humrep/deh141

Practice Committee of the American Society for Reproductive Medicine (ASRM). Testing and interpreting measures of ovarian reserve: a committee opinion. Fertil Steril.2015;103:e9e17. PMID: 25585505 DOI: 10.1016/j. fertnstert.2014.12.093

Bartmann AK, Romão GS, Ramos ES, Ferriani RA. Why do older women have poor implantation rates? A possible role of the mitochondria. J Assist Reprod Genet. 2004;21:79-83. PMID: 15202735 DOI: 10.1023/B:JARG.0000027018.02425.15

Broekmans FJ, Kwee J, Hendriks DJ, Mol BW, Lambalk CB. A systematic review of tests predicting ovarian reserve and IVF outcome. Hum Reprod Update. 2006;12:685-718. PMID: 16891297 DOI: 10.1093/humupd/dml034

Broekmans FJ, Verweij PJ, Eijkemans MJ, Mannaerts BM, Witjes $H$. Prognostic models for high and low ovarian responses in controlled ovarian stimulation using a $\mathrm{GnRH}$ antagonist protocol. Hum Reprod. 2014;29:1688-97. PMID: 24903202 DOI: 10.1093/humrep/deu090

Broer SL, Van Disseldorp J, Broeze KA, Dolleman $M$, Opmeer BC, Bossuyt P, Eijkemans MJ, Mol BW, Broekmans FJ; IMPORT Study Group. Added value of ovarian reserve testing on patient characteristics in the prediction of ovarian response and ongoing pregnancy: an individual patient data approach. Hum Reprod Update. 2013;19:2636. PMID: 23188168 DOI: 10.1093/humupd/dms041

Buyuk E, Seifer DB, Younger J, Grazi RV, Lieman H. Random anti-Müllerian hormone (AMH) is a predictor of ovarian response in women with elevated baseline early follicular follicle-stimulating hormone levels. Fertil Steril. 2011;95:2369-72. PMID: 21497340 DOI: 10.1016 / j.fertnstert.2011.03.071

Chang Y, Li J, Li X, Liu H, Liang X. Egg quality and pregnancy outcome in young infertile women with diminished ovarian reserve. Med Sci Monit. 2018;24:7279-84. PMID: 30310048 DOI: $10.12659 /$ MSM.910410

Chuang CC, Chen CD, Chao KH, Chen SU, Ho HN, Yang YS. Age is a better predictor of pregnancy potential than basel follicle-stimulating hormone levels in women undergoing in vitro fertilization. Fertil Steril. 2003;79:63-8. PMID: 12524065 DOI: $10.1016 /$ S0015-0282(02)04562-4
Creus M, Peñarrubia J, Fábregues F, Vidal E, Carmona F, Casamitjana R, Vanrell JA, Balasch J. Day 3 serum inhibin-B and $\mathrm{FSH}$ and age as predictors of assisted reproduction treatment outcome. Hum Reprod. 2000;15:2341-6. PMID: 11056129 DOI: $10.1093 /$ humrep/15.11.2341

Demko ZP, Simon AL, McCoy RC, Petrov DA, Rabinowitz M. Effects of maternal age on euploidy rates in a large cohort of embryos analyzed with 24-chromosome single-nucleotide polymorphism-based preimplantation genetic screening. Fertil Steril. 2016;105:1307-3. PMID: 26868992 DOI: $10.1016 /$ j.fertnstert.2016.01.025

Fang T, Su Z, Wang L, Yuan P, Li R, Ouyang N, Zheng L, Wang W. Predictive value of age-specific FSH levels for IVF-ET outcome in women with normal ovarian function. Reprod Biol Endocrinol. 2015;13:63. PMID: 26082101 DOI: $10.1186 / \mathrm{s} 12958-015-0056-6$

Gingold JA, Lee JA, Whitehouse MC, Rodriguez-Purata J, Sandler B, Grunfeld L, Mukherjee T, Copperman AB. Maximum baseline FSH predicts reproductive outcome better than cyclespecific baseline FSH levels: waiting for a "better" month conveys limited retrieval benefits. Reprod Biol Endocrinol. 2015;13:91. DOI: $10.1186 / s 12958-015-0078-0$

Hamdine O, Eijkemans MJ, Lentjes EW, Torrance HL, Macklon NS, Fauser BC, Broekmans FJ. Ovarian response prediction in $\mathrm{GnRH}$ antagonist treatment for IVF using antiMüllerian hormone. Hum Reprod. 2015;30:170-8. PMID: 25355590 DOI: 10.1093/humrep/deu266

Huang LN, Jun SH, Drubach N, Dahan MH. Predictors of in vitro fertilization outcomes in women with highest folliclestimulating hormone levels $\geq 12$ IU/L: a prospective cohort study. PLoS One. 2015;10:e0124789. DOI: 10.1371/ journal.pone.0124789

Jayaprakasan K, Campbell B, Hopkisson J, Johnson I, Raine-Fenning N. A prospective, comparative analysis of anti-Müllerian hormone, inhibin- $B$, and three-dimensional ultrasound determinants of ovarian reserve in the prediction of poor response to controlled ovarian stimulation. Fertil Steril. 2010;93:855-64. PMID: 19046583 DOI: 10.1016/j. fertnstert.2008.10.042

Kushnir VA, Safdie M, Darmon SK, Albertini DF, Barad DH, Gleicher N. Age-specific IVF outcomes in infertile women with baseline FSH levels $\geq 20 \mathrm{mIU} /$ mL. Reprod Sci. 2018;25:893-8. PMID: 28264624 DOI: $10.1177 / 1933719117697130$

La Marca A, Ferraretti AP, Palermo R, Ubaldi FM. The use of ovarian reserve markers in IVF clinical practice: a national consensus. Gynecol Endocrinol. 2016;32:1-5. PMID: 26531067 DOI: $10.3109 / 09513590.2015 .1102879$

La Marca A, Grisendi V, Giulini S, Argento C, Tirelli A, Dondi G, Papaleo $E$, Volpe A. Individualization of the FSH starting dose in IVF/ICSI cycles using the antral follicle count. J Ovarian Res. 2013;6:11. PMID: 23388048 DOI: 10.1186/1757-2215-6-11.

La Marca A, Papaleo E, Grisendi V, Argento C, Giulini S, Volpe A. Development of a nomogram based on markers of ovarian reserve for the individualisation of the folliclestimulating hormone starting dose in in vitro fertilisation cycles. BJOG. 2012;119:1171-9. PMID: 22805536 DOI: 10.1111/j.1471-0528.2012.03412.x. 
La Marca A, Sighinolfi G, Radi D, Argento C, Baraldi E, Artenisio AC, Stabile G, Volpe A. Anti-Mullerian hormone $(\mathrm{AMH})$ as a predictive marker in assisted reproductive technology (ART). Hum Reprod Update. 2010;16:113-30. PMID: 19793843 DOI: 10.1093/humupd/dmp036

Leijdekkers JA, Eijkemans MJC, Van Tilborg TC, Oudshoorn SC, McLernon DJ, Bhattacharya S, Mol BWJ, Broekmans FJM, Torrance HL; OPTIMIST group. Predicting the cumulative chance of live birth over multiple complete cycles of in vitro fertilization: an external validation study. Hum Reprod. 2018;33:1684-95. PMID: 30085143 DOI: 10.1093/humrep/dey263

Levin D, Jun SH, Dahan MH. Predicting pregnancy in women undergoing in-vitro fertilization with Baseline serum follicle stimulating hormone levels between 10.0 and $11.9 \mathrm{IU} / \mathrm{L}$. J Turk Ger Gynecol Assoc. 2015;16:5-10. PMID: 25788842 DOI: $10.5152 /$ jtgga.2015.15218

Ligon S, Lustik M, Levy G, Pier B. Low antimüllerian hormone $(A M H)$ is associated with decreased live birth after in vitro fertilization when follicle-stimulating hormone and AMH are discordant. Fertil Steril. 2019;112:73-81.e1. PMID: 31056310 DOI: 10.1016/j.fertnstert.2019.03.022

Lukaszuk K, Liss J, Kunicki M, Jakiel G, Wasniewski T, Woclawek-Potocka I, Pastuszek E. Anti-Müllerian hormone $(\mathrm{AMH})$ is a strong predictor of live birth in women undergoing assisted reproductive technology. Reprod Biol. 2014;14:176-81. PMID: 25152514 DOI: 10.1016/j. repbio.2014.03.004

Metello JL, Tomás C, Ferreira P. Can we predict the IVF/ ICSI live birth rate? JBRA Assist Reprod. 2019;23:402-7. PMID: 31361435 DOI: 10.5935/1518-0557.20190043

McLernon DJ, Steyerberg EW, Te Velde ER, Lee AJ, Bhattacharya S. Predicting the chances of a live birth after one or more complete cycles of in vitro fertilisation: population based study of linked cycle data from 113873 women. BMJ. 2016;355:i5735. PMID: 27852632 DOI: 10.1136/bmj.i5735

Nelson SM. Biomarkers of ovarian response: current and future applications. Fertil Steril. 2013;99:963-9. PMID: 23312225 DOI: 10.1016/j.fertnstert.2012.11.051

Nelson SM, Lawlor DA. Predicting live birth, preterm delivery, and low birth weight in infants born from in vitro fertilisation: a prospective study of 144,018 treatment cycles. PLoS Med. 2011;8:e1000386. PMID: 21245905 DOI: $10.1371 /$ journal.pmed.1000386

Nelson SM, Klein BM, Arce JC. Comparison of antimüllerian hormone levels and antral follicle count as predictor of ovarian response to controlled ovarian stimulation in good-prognosis patients at individual fertility clinics in two multicenter trials. Fertil Steril. 2015;103:923-930.e1. PMID: 25624196 DOI: 10.1016/j.fertnstert.2014.12.114

Papaleo E, Zaffagnini S, Munaretto M, Vanni VS, Rebonato G, Grisendi V, Di Paola R, La Marca A. Clinical application of a nomogram based on age, serum FSH and AMH to select the FSH starting dose in IVF/ICSI cycles: a retrospective two-centres study. Eur J Obstet Gynecol Reprod Biol. 2016;207:94-9. PMID: 27835829 DOI: $10.1016 / \mathrm{j}$. ejogrb.2016.10.021
Pastore LM, Christianson MS, Stelling J, Kearns WG, Segars $\mathrm{JH}$. Reproductive ovarian testing and the alphabet soup of diagnoses: DOR, POI, POF, POR, and FOR. J Assist Reprod Genet. 2018;35:17-23. PMID: 28971280 DOI: 10.1007/ s10815-017-1058-4

Simon AL, Kiehl M, Fischer E, Proctor JG, Bush MR, Givens C, Rabinowitz M, Demko ZP. Pregnancy outcomes from more than 1,800 in vitro fertilization cycles with the use of 24-chromosome single-nucleotide polymorphism-based preimplantation genetic testing for aneuploidy. Fertil Steril. 2018;110:113-21. PMID: 29908770 DOI: 10.1016 /j.fertnstert.2018.03.026

Tal R, Seifer DB. Ovarian reserve testing: a user's guide. Am J Obstet Gynecol. 2017;217:129-40. PMID: 28235465 DOI: $10.1016 /$ j.ajog.2017.02.027

Thum MY, Kalu E, Abdalla H. FSH basal elevada e qualidade do embrião: lições de embriões de cultura estendida: FSH elevada e qualidade do blastocisto. J Assist Reprod Genet. 2009; 26: 313-8. PMID: 19513823

Toner JP. Idade $=$ qualidade do ovo, nível de FSH = quantidade de ovo. Fertil Steril. 2003; 79: 491. PMID: 12620427

Tsakos E, Tolikas A, Daniilidis A, Asimakopoulos B. Valor preditivo do hormônio anti-Mülleriano, hormônio folículo-estimulante e contagem do folículo antral no resultado da estimulação ovariana em mulheres seguindo protocolo de antagonista de GnRH para FIV / ET. Arch Gynecol Obstet. 2014; 290: 1249-53. PMID: 25001569 DOI: 10.1007/s00404-014-3332-3

Vaegter KK, Lakic TG, Olovsson M, Berglund L, Brodin T, Holte J. Quais fatores são mais preditivos para nascidos vivos após fertilização in vitro e tratamentos de injeção intracitoplasmática de espermatozoide (FIV / ICSI)? Análise de 100 variáveis registradas prospectivamente em 8.400 transferências de embrião único FIV / ICSI. Fertil Steril. 2017; 107: 641-8.e2. PMID: 28108009 DOI: $10.1016 /$ j.fertnstert.2016.12.005

Van Loendersloot LL, Van Wely M, Limpens J, Bossuyt PM, Repping S, Van Der Veen F. Predictive factors in in vitro fertilization (IVF): a systematic review and meta-analysis. Hum Reprod Update. 2010;16:577-89. PMID: 20581128

Van Loendersloot LL, Van Wely M, Repping S, Bossuyt PM, Van Der Veen F. Individualized decision-making in IVF: calculating the chances of pregnancy. Hum Reprod. 2013;28:2972-80. PMID: 23925394 DOI: 10.1093/ humrep/det315

Van Rooij IA, Bancsi LF, Broekmans FJ, Looman CW, Habbema JD, Te Velde ER. Women older than 40 years of age and those with elevated follicle-stimulating hormone levels differ in poor response rate and embryo quality in in vitro fertilization. Fertil Steril. 2003;79:482-8. PMID: 12620425 DOI: $10.1016 /$ S0015-0282(02)04839-2

Wang S, Zhang Y, Mensah V, Huber WJ 3rd, Huang YT, Alvero R. Discordant anti-Müllerian hormone (AMH) and follicle stimulating hormone (FSH) among women undergoing in vitro fertilization (IVF): which one is the better predictor for live birth?. J Ovarian Res. 2018;11:60. PMID: 30012195 DOI: 10.1186/s13048-018-0430-z 